\title{
Evidence for zoonotic transmission of species A rotavirus from goat and cattle in nomadic herds in Morocco, 2012-2014
}

\author{
Sanaâ Alaoui Amine ${ }^{1,2}$ (D) Marouane Melloul ${ }^{1,2} \cdot$ Moulay Abdelaziz El Alaoui ${ }^{2,3} \cdot$ Hassan Boulahyaoui ${ }^{1}$. \\ Chafiqa Loutfi ${ }^{4} \cdot$ Nadia Touil $^{1,5} \cdot$ Elmostafa El Fahime ${ }^{1,2}$
}

Received: 25 December 2019 / Accepted: 28 June 2020 / Published online: 10 July 2020

(c) Springer Science+Business Media, LLC, part of Springer Nature 2020

\begin{abstract}
Species A rotaviruses (RVAs) are a leading cause of diarrhea in children and in the young of a large variety of mammalian and avian host species. The purpose of this study was to identify RVA in nomadic goats and calves during severe diarrhea outbreaks in 2012 and 2014 in Bouaarfa, Morocco, and to characterize the complete genomic constellation of two bovine and caprine strains (S18 and S19) and their genetic relatedness with the human strain ma31 detected in 2011 in Morocco. Partial nucleotide sequencing of VP4 and VP7 genes for the twenty-two positive samples revealed three circulating genotypes: G6P[14], G10P[14], and G10P[5] with predominance of G6P[14] genotype. Full-genome sequencing for both strains S18 and S19 presented, respectively, the following genomic constellations: G6-P[14]-I2-R2-C2-M2-A3-N2-T6-E2-H3 and G10P[14]-I2-R2-C2-M2-A11-N2-T6-E2-H3. Phylogenetic analyses and the analysis of the VP8* antigenic epitopes for S18, S19 and ma31 revealed a shared similarity with bovine, caprine, ovine and human strains from Morocco and other countries. The VP2 and NSP1 genes of the S19 strain were closely related to those of the cognate genes of the human ma31 strain, while the VP4 gene of S18 strain was closely related to the cogent gene of the ma31 strain. Our findings revealed cases of zoonotic transmission and confirmed the risk of emergence of new genotypes in some environments such as nomadic regions, where close physical proximity between human and livestock is common. The present study is novel in reporting whole-genome analyses of RVA isolates obtained from nomadic livestock in Morocco.
\end{abstract}

Keyword Group A rotavirus · Whole-genome analysis · Interspecies transmission · Moroccan nomadic populations

\section{Introduction}

Edited by Juergen A Richt.

Electronic supplementary material The online version of this article (https://doi.org/10.1007/s11262-020-01778-w) contains supplementary material, which is available to authorized users.

Sanaâ Alaoui Amine

salaoui16@yahoo.fr

1 Genomic Center for Human Pathologies (GENOPATH), Faculty of Medicine and Pharmacy, University Mohammed V in Rabat, Av. Mohamed Belarbi El Alaoui, 6203 Rabat, Morocco

2 Molecular Biology and Functional Genomics Platform, National Center for Scientific and Technical Research, CNRST, Angle Avenue Allal El Fassi, Avenue des FAR, Quartier Er-Ryad, 8027 Rabat, Morocco
Species A rotaviruses (RVAs) (family Reoviridae) are one of the most important pathogens of the gastrointestinal tract causing severe acute diarrhea mainly in children and many young animal species worldwide [1,2]. In children, the gastroenteritis not well managed may lead to death. In animals, rotavirus infection can lead to colossal financial losses due

3 Virology Laboratory, Research Team in Molecular Virology and Onco Biology (ERVMOB), Faculty of Medicine and Pharmacy, University Mohammed V in Rabat, Av. Mohamed Belarbi El Alaoui, 6203 Rabat, Morocco

4 Département de Virologie, Société de Productions Biologiques et Pharmaceutiques Vétérinaires, Km 2, Route de Casablanca, B.P. 4569 Rabat, Morocco

5 Research and Biosafety Laboratory, Med V Military Teaching Hospital in Rabat, 10045 Hay Ryad, Morocco 
to a decrease in productivity mainly in developing countries such as Africa and Asia [3].

The RVA genome consists of 11 segments of doublestranded RNA (dsRNA) encoding six structural viral proteins (VP1 to VP4, VP6, and VP7) and six non-structural viral proteins (NSP1 to NSP5/6) [4]. Genome segment 11 codes for two proteins: NSP5 and NSP6 [5].

RVA can be categorized by a dual classification system, based on the two out capsid proteins VP7 and VP4 that determine G (VP7) and P (VP4) genotypes [6]. Recently, RVAs have been classified based on the nucleotide sequence identity cut-off values of all the 11 segments since all genes are subject to mutations, reassortment and recombination events [7, 8]. Until now $36 \mathrm{G}$ types and 51P types have been identified in humans and animals $[9,10]$ according to the Rotavirus Classification Working Group (RCWG) (https:// rega.kuleuven.be/cev/viralmetagenomics/virus-classifica tion/rcwg). This last classification combined with complete genome sequencing and phylogenetic analysis has been applied to elucidate the evolutionary mechanisms through which the strain under study has emerged and to determine potential origins of new strains [11-13]. This has led to obtain conclusive information and vital insights on the complex genetic diversity of rotavirus strains.

Interspecies transmission of RVA may lead to the emergence of novel strains; this mechanism contributes greatly to the diversity of the virus in both animals and humans. Other mechanisms are involved in the rotavirus evolution such as gene reassortment, gene recombination and accumulation of point mutations [2]. The combination of two of these mechanisms between RVAs of different species can lead to the rise and spread of novel genotypes [14].

In Morocco, the Bedouin livestock farming systems that are present in several regions of the country may favor the introduction of new strains from a heterologous host to human by interspecies transmission considering their nomadic lifestyle. Due to the high mobility of livestock and the temporary character of the nomadic settlements, no study identified the circulating RVAs causing sudden seasonal disease outbreaks of diarrhea in sheep, goats, dromedaries and cattle. Besides, this infectious disease can have serious negative repercussions on the livestock economy for nomadic farmers, given the large economic impact that represents the breeding of ruminants in these regions. Few studies have been conducted at the dairy farm level in Morocco for the detection of RVA; it was shown that in calves G10P[14] and G6P[5] are the most circulating genotypes [15]. In other neighboring countries such as Tunisia, a study was done on dairy calves to determine the prevalence of rotavirus infection and the genomic diversity of bovine rotavirus strains. The most common genotypes found were G6P[11] and G10P[11], and the genotype G10P[14] was seen in only one specimen [16]. In Western Algeria, the prevalence of bovine rotavirus and bovine coronavirus was determined in feces from diarrheic calves. It showed that both bovine coronavirus and rotavirus are involved in the neonatal calves diarrhea with a high prevalence for bovine coronavirus compared to rotavirus [17, 18].

The first purpose of this study was to provide some insights into the circulation of RVA in nomadic goats and calves during severe outbreaks of diarrhea which occurred in 2012 and 2014 in Bouaarfa, a nomadic region in Eastern part of Morocco. The second objective was the determination of the complete genome constellation of one caprine and one bovine RVA strain using the full-genome sequencing to obtain more information about the genetic relatedness with a rare human genotype G8P [14] detected in a child for the first time in Morocco [19]. The amino acid sequence comparison of the VP8* antigenic region between the caprine, the bovine and the human strains and other relevant strains was also conducted. In the meantime, the possible interspecies transmission events of RVA in this circumstance are also discussed.

\section{Materials and methods}

\section{Sampling}

A total of 30 diarrheic fecal samples were collected from young goats (19) and calves (11) during severe outbreaks of acute diarrhea in 2012 and 2014 in Bouaarfa, a region of nomadic farmers in Eastern part of Morocco.

\section{Detection of RVA}

Fecal samples were identified as positive for RVA using the rapid test (Duo Rota-Adenovirus-Check-1, VEDA LAB, France) according to the manufacturer's instruction.

\section{Viral dsRNA extraction}

$10 \%$ of fecal suspension was prepared in PBS. The homogenate was centrifuged at $5000 \times g$ for $15 \mathrm{~min}$ and the supernatant collected. Total viral RNA was extracted from $140 \mu$ of the supernatant using QIAamp Viral RNA Mini Kit (Qiagen, Inc., Valencia, CA) following the manufacture's instructions. Viral RNA was eluted in $50 \mu \mathrm{l}$ of elution buffer and stored at $-80{ }^{\circ} \mathrm{C}$.

\section{RT-PCR and partial nucleotide sequencing}

The extracted viral RNA was reverse transcribed (RT) using Tetro cDNA Synthesis kit (Bioline, London, UK) following the manufacturer's instructions. PCRs were performed using specific primers targeting VP4 and VP7 
genes and MyFi Mix (Bioline, London, UK) as described previously [20,21]. The PCR products were purified using ExoSAP-IT purification kit (Thermo Fisher Scientific, Waltham, MA) according to the manufacture's protocol. Nucleotide sequences were determined using Big Dye Terminator Cycle Sequencing kit v3.1 (Life technologies, Inc. Foster City, CA) on an ABI Prism 3130XL Genetic Analyzer (Life technologies, Inc. Foster City, CA).

\section{Genotype assignment}

RVA genotypes were assigned to VP7 and VP4 gene segments of positive strains using the online rotavirus genotyping tool, RotaC v2.0 [22].
The partial sequences of VP7 and VP4 genes were deposited into the GenBank sequence database under accession numbers KT461271 through MN583318 (Table 1).

\section{Full-length genome sequencing of bovine strain (S18) and caprine strain (S19)}

Two out of 22 bovine and caprine RVA positive samples were selected for whole-genome sequencing. The strain RVA/Calf-wt/MAR/S18/2012/G6P[14] was selected because its VP4 gene sequence is $100 \%$ identical to that of the human strain ma31 [19]. The selection of the second strain RVA/ Goat-wt/MAR/S19/2012/G10P[14] among the caprine RVA samples was based on the availability of sufficient material allowing whole-genome sequencing directly from the fecal sample.
Table 1 Record data from thirty fecal samples collected during 2012 and 2014 in Bouaarfa, Eastern part of Morocco

\begin{tabular}{|c|c|c|c|c|c|c|}
\hline $\begin{array}{l}\text { Samples } \\
\text { identifica- } \\
\text { tion }\end{array}$ & Age by days & Host & $\begin{array}{l}\text { Duo Rota-Adenovi- } \\
\text { rus-Check-1 rapid } \\
\text { test }\end{array}$ & Genotypes & $\begin{array}{l}\text { VP4 } \\
\text { Accession } \\
\text { numbers }\end{array}$ & $\begin{array}{l}\text { VP7 } \\
\text { Accession } \\
\text { numbers }\end{array}$ \\
\hline Ch_S10 & 10 & Young goat & + & G6P[14] & KT461271 & KT461280 \\
\hline Ch_S11 & 8 & Young goat & + & G6P[14] & KT461274 & KT461283 \\
\hline Ch_S111 & 10 & Young goat & + & G6P[14] & KT461275 & KT461284 \\
\hline Ch_S31 & 4 & Young goat & + & G6P[14] & KT461276 & KT461285 \\
\hline Ch_S61 & 15 & Young goat & + & G6P[14] & KT461277 & KT461286 \\
\hline Ch_S44 & 20 & Young goat & + & G10P[14] & KT461279 & KT461288 \\
\hline Ch_S2 & 15 & Young goat & + & G6P[14] & KT461272 & KT461281 \\
\hline Ch_S12 & 10 & Young goat & + & G6P[14] & KT461278 & KT461287 \\
\hline Ch_S22 & 10 & Young goat & + & G6P[14] & KT461273 & KT461282 \\
\hline S1 & 10 & Calf & + & GxP[14] & MN583319 & - \\
\hline $\mathrm{S} 2$ & 10 & Calf & + & G10P[14] & MN583320 & MN583315 \\
\hline $\mathrm{S} 3$ & 10 & Calf & + & GxP[14] & MN583321 & - \\
\hline S4 & 22 & Calf & + & GxP[14] & MN583322 & \\
\hline S5 & 14 & Young goat & + & G6P[14] & MN583323 & MN583316 \\
\hline S6 & 16 & Calf & + & GxP[14] & MN583324 & - \\
\hline S7 & 10 & Calf & + & GxP[14] & MN583325 & \\
\hline S8 & 22 & Young goat & + & GxP[14] & MN583326 & - \\
\hline S9 & 25 & Calf & + & GxP[14] & MN583327 & - \\
\hline S10 & 15 & Young goat & - & - & - & - \\
\hline S11 & 15 & Calf & - & - & - & - \\
\hline $\mathrm{S} 12$ & 60 & Young goat & + & G10P[14] & MN583328 & MN583317 \\
\hline S13 & 21 & Calf & - & - & - & - \\
\hline S14 & 60 & Calf & - & - & - & - \\
\hline S15 & 7 & Young goat & + & G10P[5] & MN583329 & MN583318 \\
\hline S16 & 6 & Young goat & - & - & - & - \\
\hline S17 & 7 & Young goat & - & - & - & - \\
\hline S18 & 15 & Calf & + & G6P[14] & MN067458 & MN067460 \\
\hline S19 & 7 & Young goat & + & G10P[14] & MN067447 & MN067449 \\
\hline S20 & 10 & Young goat & - & - & - & - \\
\hline S21 & 8 & Young goat & - & - & - & - \\
\hline
\end{tabular}

(+) Positive samples for RVA (rapid test Rota-Adenovirus-Check-1, VEDA LAB, France). (-) Negative samples for RVA (rapid test Rota-Adenovirus-Check-1, VEDA LAB, France). (X) Undetermined genotypes 


\section{Whole-genome amplification}

The cDNA of each rotavirus gene segment (11 segments) of the two strains S18 and S19 was subjected to PCR using specific primers in addition to newly designed primers (Supplementary Table 1) and MyFi Mix (Bioline, London, UK) according to manufacturer's instruction. The amplification conditions were $95^{\circ} \mathrm{C}$ for $2 \mathrm{~min}, 35$ cycles of $95^{\circ} \mathrm{c}$ for $1 \mathrm{~min}$, $60{ }^{\circ} \mathrm{C}$ for $1 \mathrm{~min}$, and $72{ }^{\circ} \mathrm{C}$ for 1 to $5 \mathrm{~min}$ depending on the length of cDNA, followed by final extension at $72{ }^{\circ} \mathrm{C}$ for $8 \mathrm{~min}$. Amplicons were separated on $1.5 \%$ agarose gels containing ethidium bromide $(0.5 \mu \mathrm{g} / \mathrm{ml})$ and visualized under UV transilluminator.

\section{Nucleotide sequencing}

Purification of the PCR products was done by ExoSAP-IT purification kit (Thermo Fisher Scientific, Waltham, MA) according to the manufacture's protocol. Amplicons were sequenced with the Big Dye Terminator Cycle Sequencing kit v3.1 (Life technologies, Inc. Foster City, CA) using the same primers used for PCR, in addition to primers used exclusively for sequencing. To recover the entire sequence fragments including the $5^{\prime}$ and $3^{\prime}$ termini of the 11 gene segments, Primer walking strategy was conducted. For VP3 and NSP1 genes, primers were newly designed to recover the complete open reading frame (ORF) sequences (Supplementary Table 2). The percentage of the novel sequence for each gene was also calculated based on the nucleotide length of the primers used for sequencing and the length of the respective gene obtained (Supplementary Table 3).

The sequence data was collected from an ABI Prism 3130XL Genetic analyzer (Life technologies, Inc. Foster City, CA). The sequences were edited and assembled using DNA Dragon Sequence Assembler version 1.6.0 (SequentixDigital DNA Processing, Germany).

RotaC version 2 (https://rotac.regatools.be), a classification tool for RVAs, was used to assign genotypes to the eleven gene segments.

\section{Phylogenetic analysis}

Phylogenetic and molecular evolutionary analyses were conducted using the MEGA 6 software [23]. Multiple sequence alignments were conducted utilizing the MUSCLE program. Maximum likelihood phylogenetic trees were constructed using models of nucleotide substitutions based on the lowest Bayesian Information Criterion (BIC) scores [24]: GTR+G+I (NSP1 and VP3), T92+G(NSP2, NSP3, NSP4, VP6 and VP7), TN93+G+I (VP2 and VP4), GTR+I (VP1) and T92+G+I (NSP5) in the MEGA 6 software. The trees were constructed using bootstrap resampling analysis at 1000 replicates. Amino acid alignment for VP4 gene was performed using MEGA 6 software.

\section{Sequence submission}

The nucleotide sequences of all genome segments of both strains were deposited in the National Centre of Biotechnology Information (NCBI) database, GenBank, under the accession numbers from MN067450 (NSP1) to MN067460 (VP7) for S18 and from MN067439 (NSP1) to MN067449 (VP7) for S19 (Supplementary Table 4).

\section{Results}

\section{Characterization of the genotypes of RVA strains circulating in the Bouaarfa region}

The area of Bouaarfa is located in the oriental region in North-Eastern Morocco. Steppes of Alfa and sagebrush are the basis for the regional farming production. The pastoral tradition is well established among the tribes of the region with nomadic vocation. Indeed this area is overwhelmingly inhabited by nomadic pastoral communities who make use of this harsh environment, keeping sheep, goats, camels, and cattle together. In April 2012 and 2014, thirty diarrheic fecal samples were collected from cattle and goats (eleven calves and nineteen young goats) during a severe outbreak in nomadic livestock in this region. Among the 30 diarrheic fecal samples collected, RVAs were detected in twenty-two samples by the Duo RotaAdenovirus-Check-1, rapid test. These positive samples were obtained from different nomadic farmers established in remote areas in this vast region.

By analysis of partial nucleotide sequences, the VP7 and VP4 genes of the positive samples from both caprine and bovine origin were assigned to G6P[14] for ten (45.45\%) samples, G10P[14] for four (18.18\%) samples, and G10P[5] for one (4.54\%) sample. Successful partial genome sequencing was possible in fifteen $(68.18 \%)$ of the positive calf and goat fecal samples. Thus, for some strains, undetermined genotypes were attributed to the VP7 gene such as S1, S3, S4, S6, S7, S8 and S9 (Table 1). The RVA strains isolated from young goats presented three different genotypes: G6P[14], G10P[14] and G10P[5], whereas the VP7 gene could not be identified in all calf fecal samples, except for S2 and S18. On the other hand, the $\mathrm{P}[14]$ genotype was found for all positive samples, except for one strain S15, whose genotype has been determined as G10P[5] (Table 1). 


\section{Nucleotide sequencing and full-genome-based genotyping of strains S18 and S19}

The genotypes of the 11 genes of S18 and S19 strains were assigned as G6-P[14]-I2-R2-C2-M2-A3-N2-T6-E2-H3 and G10-P[14]-I2-R2-C2-M2-A11-N2-T6-E2-H3, respectively, using the RotaC database. These genotypes constellations were found to be on a DS-1-like genetic backbone (I2-R2C2-M2-A2-N2-T2-E2-H2). However, for the two strains, NSP5 was AU-1-like and NSP3 was the T6 genotype. NSP1 was A3/11 genotypes for S18 and S19, respectively.

\section{Constellation comparison}

Comparison of the complete genotype constellation of the studied strains with the human Moroccan strain ma31 and other bovine and non-bovine strains is shown in Supplementary Table 5.

S18 and S19 strains were found to share a largely conserved non-G genotype constellation (P[14]-I2-R2-C2-M2(A3/11)-N2-T6-E2-H3) which is commonly found in bovinelike strains. The constellation of the bovine strain S18 is completely identical to the human strains from Italy (PA169, 111-05-27), Belgium (B10925) and Thailand (SKT-27) with eleven shared genotypes, while some strains from human and animal origin share nine genotypes with S18 such as the human strain ma31 from Morocco, the bovine strain 1604 from South Africa and the Macaque strain PTRV from United States. The Chubut strain and the caprine strain 0040 from Argentina share eight and seven genotypes, respectively, with the bovine strain S18. The latter shares also the same constellation with human G8 RVAs such as PR1300 and PR1973 (Italy) (Supplementary Table 5). The caprine strain S19 present an identical constellation with the human strains V585 and PR457 from Australia and Italy, respectively, thus eleven genotypes are shared. Other animal and human strains share ten genotypes with S19 like the ovine strain OVR762 from Spain and the human strains ma31, MG6, N-1, EGY3399, BA02, Hun5, BP1879, BP1062 and 182-02 from Morocco, Australia, India, Egypt, Italy, and Hungary, respectively (Supplementary Table 5). Also, the comparison of the constellations of the S18 and S19 isolates shows that they have nine genotypes in common and the majority of the human and animal strains present the same genotype with S18 and S19 for nine genes VP4, VP6, VP1VP3, NSP2-NSP5 (Supplementary Table 5).

\section{Phylogenetic analyses}

We constructed phylogenetic trees for the full-length gene sequence of each of the eleven gene segments of Moroccan RVA strains: the caprine strain S19 and the bovine strain S18, together with appropriate human and animal RVA strains. We also calculate the nucleotide sequence identity for strains selected for phylogenetic analyses. The strains in NCBI database that had the highest sequence identity with the bovine and the caprine RVA strains of this study are given in Table 2.

Phylogenetic analysis showed that NSP2, VP4 and VP6 genes for S18 strain and NSP1, NSP2, NSP4, VP2, VP3 and VP6 genes for S19 strain clustered with human RVA strains, while the rest of the genes for both S18 and S19 were closely related to animal strains (Table 2 and Fig. 1a-k).

The VP7 genes of Moroccan bovine strain S18 and caprine strain S19 exhibited the highest nucleotide sequence identity $(97.55 \%$ and $96.10 \%$, respectively) with French bovine strain V025 (G6P[5]) and Thai caprine strain 61A (G10P[5]) (Fig. 1a). The S18 strain belonged to lineage IV of the G6 genotype, while the caprine strain S19 belonged to lineage VII of the G10 genotype. The human strain ma31 with its G8 genotype was too far from the other Moroccan strains in the VP7 tree.

The VP4 genes of P[14] strains S18 and S19 exhibited the maximum nucleotide sequence identity $(100 \%$ and $95.85 \%$, respectively) with the Moroccan bovine-like human strain ma31 (G8P[14]) and the Argentinean Guanaco strain Chubut (G8P[14]) (Table 2 and Fig. 1b). Phylogenetically, S18 and S19 strains belonged to lineage I which includes human, goat, cow, sheep and antelope strains. Furthermore, we compared the putative VP8* antigenic epitopes of S18 and S19 strains with those of selected P[14] strains (Fig. 2). The antigenic epitope 8-1 of S18 and S19 strains appeared to be conserved with those of RVA P [14] strains from different species (human, bovine and ovine). RVA/Human-tc/MAR/ ma31/2011/G8P[14], RVA/BOV/MAR/Bas1:2S/2014/P[14], RVA/BOV/MAR/Bas2:6S/2014/P[14], RVA/Human-wt/ BEL/B10925/1997/G6P[14] and RVA/Human-wt/GHA/ M0084/2010/G6P[14] carried very similar neutralizing epitopes as that of S18 strain. However, differences were observed at four amino acid positions, three at 8-3 (S113P and N114S for goat and guanaco strains; N133D for human, guanaco and ovine strains) and one at 8-4 (I89V) (Fig. 2). The analysis of the neutralizing epitopes along with phylogenetic analysis suggested that the VP4 gene of the Moroccan human strain ma31 was a result of an interspecies transmission from bovine-like rotavirus to human.

The VP6 gene of S18 strain showed the maximum nucleotide sequence identity $(97.05 \%)$ with the VP6 gene of the Thai human strain SKT-27 (G6P[14]) [25] having a DS1-like genetic backbone. While the VP6 gene of S19 strain showed the highest nucleotide sequence identity $(98.30 \%)$ with the VP6 gene of the Italian human strain 111-05-27 (G6P[14]) [7] (Table 2 and Fig. 1c).

The VP1 genes of strains S18 and S19 exhibited the maximum nucleotide sequence identity $(96.31 \%$ and $94.73 \%$, respectively) with the bovine strain $\mathrm{RF}$ (G6P[6]) and the 
Table 2 Percentage identities of the most closely related nucleotide sequences of the complete genome segments of rotavirus strains listed in the GenBank compared to the bovine strain (S18) and the caprine strain (S19)

\begin{tabular}{|c|c|c|c|c|c|c|c|c|}
\hline \multirow[t]{2}{*}{ Genes } & \multirow[t]{2}{*}{ Genotype } & \multicolumn{3}{|c|}{ RVA/Calf-wt/MAR/S18/2012/G6P[14] } & \multicolumn{4}{|c|}{ RVA/Goat-wt/MAR/S19/2012/G10P[14] } \\
\hline & & Closely related strain & $\mathrm{NA}^{\mathrm{a}}(\%)$ & Accession number & Genotype & Closely related strain & $\mathrm{NA}^{\mathrm{a}}(\%)$ & Accession number \\
\hline NSP1 & A3 & $\begin{array}{l}\text { RVA/Cow-tc/JPN/ } \\
\text { NCDV/XXXX/ } \\
\text { GXP[X] }\end{array}$ & 96.48 & GU808570 & A11 & $\begin{array}{r}\text { RVA/Human-tc/MAR/ } \\
\text { ma31/2011/G8P[14] }\end{array}$ & 98.55 & MG214332 \\
\hline NSP2 & $\mathrm{N} 2$ & $\begin{array}{l}\text { RVA/Human-wt/THA/ } \\
\text { CMH-N165-13/2013/ } \\
\text { G8P[8] }\end{array}$ & 97.3 & MH060115 & $\mathrm{N} 2$ & $\begin{array}{l}\text { RVA/Human-wt/HUN/ } \\
\text { BP1879/2003/G6P[14] }\end{array}$ & 96.13 & FN665683 \\
\hline NSP3 & T6 & $\begin{array}{l}\text { RVA/Cow-wt/TUR/ } \\
\text { Amasya-1/2015/ } \\
\text { G8P[5] }\end{array}$ & 97.30 & KX212881 & T6 & $\begin{array}{l}\text { RVA/Cow-tc/XXX /RF/ } \\
\text { XXXX /G6P[6] }\end{array}$ & 96.37 & Z21639 \\
\hline NSP4 & E2 & $\begin{array}{l}\text { RVA/Pig-tc/THA/ } \\
\text { P343/1991/G10P[5] }\end{array}$ & 98.38 & AB972865 & E2 & $\begin{array}{l}\text { RVA/Human-wt/Bel/ } \\
\text { BEF06018/2014/ } \\
\text { G29P[41] }\end{array}$ & 95.17 & KU128901 \\
\hline NSP5 & $\mathrm{H} 3$ & $\begin{array}{l}\text { RVA/Dog-wt/ } \\
\text { GER/88,977/2013/ } \\
\text { G8P[1] }\end{array}$ & 98.20 & KJ940161 & $\mathrm{H} 3$ & $\begin{array}{l}\text { RVA/Sheep-tc/ESP/ } \\
\text { OVR762/2002/ } \\
\text { G8P[14] }\end{array}$ & 98.65 & EF554158 \\
\hline VP1 & $\mathrm{R} 2$ & $\begin{array}{l}\text { RVA/Cow-tc/XXX /RF/ } \\
\text { XXXX /G6P[6] }\end{array}$ & 96.31 & J04346 & $\mathrm{R} 2$ & $\begin{array}{l}\text { RVA/Sheep-tc/ESP/ } \\
\text { OVR762/2002/ } \\
\text { G8P[14] }\end{array}$ & 94.73 & EF554148 \\
\hline VP2 & $\mathrm{C} 2$ & $\begin{array}{l}\text { RVA/Giraffe-wt/IRL/ } \\
\text { UCD/2007/G10P[11] }\end{array}$ & 97.65 & GQ428142 & $\mathrm{C} 2$ & $\begin{array}{r}\text { RVA/Human-tc/MAR/ } \\
\text { ma31/ 2011/G8P[14] }\end{array}$ & 97.66 & MG214338 \\
\hline VP3 & M2 & $\begin{array}{l}\text { RVA/roe deer-wt/SLO/ } \\
\text { D110-15/2015/G8[14] }\end{array}$ & 97.43 & KY426811 & M2 & $\begin{array}{l}\text { RVA/Human-wt/DEU/ } \\
\text { GER29-14/2014/ } \\
\text { G6P[9] }\end{array}$ & 96.62 & KX880441 \\
\hline VP4 & $\mathrm{P}[14]$ & $\begin{array}{r}\text { RVA/Human-tc/MAR/ } \\
\text { ma31/ 2011/G8P[14] }\end{array}$ & 100 & MG214340 & $\mathrm{P}[14]$ & $\begin{array}{l}\text { RVA/Guanaco-wt/ARG/ } \\
\text { Chubut/1999/G8P[14] }\end{array}$ & 95.85 & FJ347103 \\
\hline VP6 & I2 & $\begin{array}{l}\text { RVA/Human-wt/THA/ } \\
\text { SKT-27/2012/G6P[14] }\end{array}$ & 97.05 & LC055551 & I 2 & $\begin{array}{l}\text { RVA/Human-wt/ } \\
\text { ITA/111-05-27/2005/ } \\
\text { G6P[14] }\end{array}$ & 98.30 & EF554141 \\
\hline VP7 & G6 & $\begin{array}{l}\text { RVA/Cow-wt/FRA/ } \\
\text { V025/2010/G6P[5] }\end{array}$ & 97.55 & HE646646 & G10 & $\begin{array}{l}\text { RVA/Cow-tc/ } \\
\text { THA/61A/1989/ } \\
\text { G10P[5] }\end{array}$ & 96.10 & LC133541 \\
\hline
\end{tabular}

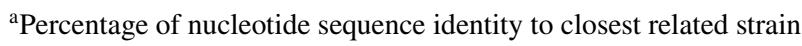

ovine strain OVR762 (G8P[14]) from Spain (Table 2). Phylogenetic analysis revealed that S18 and S19 strains were closely related to several human, bovine and bovine-like human strains from different parts of the world within the bovine-like R2 subcluster (Fig. 1d).

The analysis of the VP2 tree (Fig. 1e) revealed a very close clustering ( $97.65 \%$ nucleotide identity) of the S18 strain with the giraffe G10P[11] strain detected in Ireland in 2007 (RVA/Giraffe-wt/IRL/UCD/2007/G10P[11]), while the VP2 gene of the S19 strain clustered closely with the human strain MAR/ma31 detected in Morocco in 2011 (97.66\% nt identity) (Table 2 and Fig. 1g) which was described to be of bovine-like human origin [19].

The VP3 gene of the S18 and S19 strains clustered with the roe deer G8P[14] strain (D110-15) from Slovenia detected in 2015 (97.43\% nt identity) and the human G6P[9] strain (GER29-14) isolated in Germany in 2014 (96.62\% nt identity). The analysis of the VP3 tree showed that the ma31 strain was located too distantly from the two strains S18 and S19 although it classified within the same M2 genotype as the latter (Fig. 1f and Table 2).

Concerning non-structural genes, the NSP1 gene of S18 strain showed the maximum nucleotide sequence identity (96.48\%) with that of Japanese bovine-like human strain NCDV (Table 2), and phylogenetically, S18 strain was found to be distantly related to other human and bovine strains in the A3 genotype (Fig. 1g) on the other hand, the NSP1 gene of S19 strain clustered closely with the Moroccan human strain ma31 with $98.55 \%$ of nucleotide identity. In the phylogenetic tree, the two strains were closely related with bovine and human strains from different parts of the world in the A11 genotype (Table 2 and Fig. 1g).

NSP2 tree showed a close relationship between S18 strain and the human CMH-N165-13 strain detected in Thailand in 2013 (97.3\% nt identity). The same tree showed a very close clustering between the caprine strain S19 and the 
human BP1879 strain isolated in Hungary in 2003 presenting $96.13 \%$ of nucleotide identity (Table 2 and Fig. 1h).

For the NSP3 gene, the sequence of S18 strain clustered very well with the bovine strain (TUR/Amasya-2/2015/ G8P[5]) with $97.30 \%$ of nucleotide identity, while the S19 strain presented a maximum nucleotide sequence identity (96.37\%) with the bovine strain RF (G6P[6]) (Table 2), the
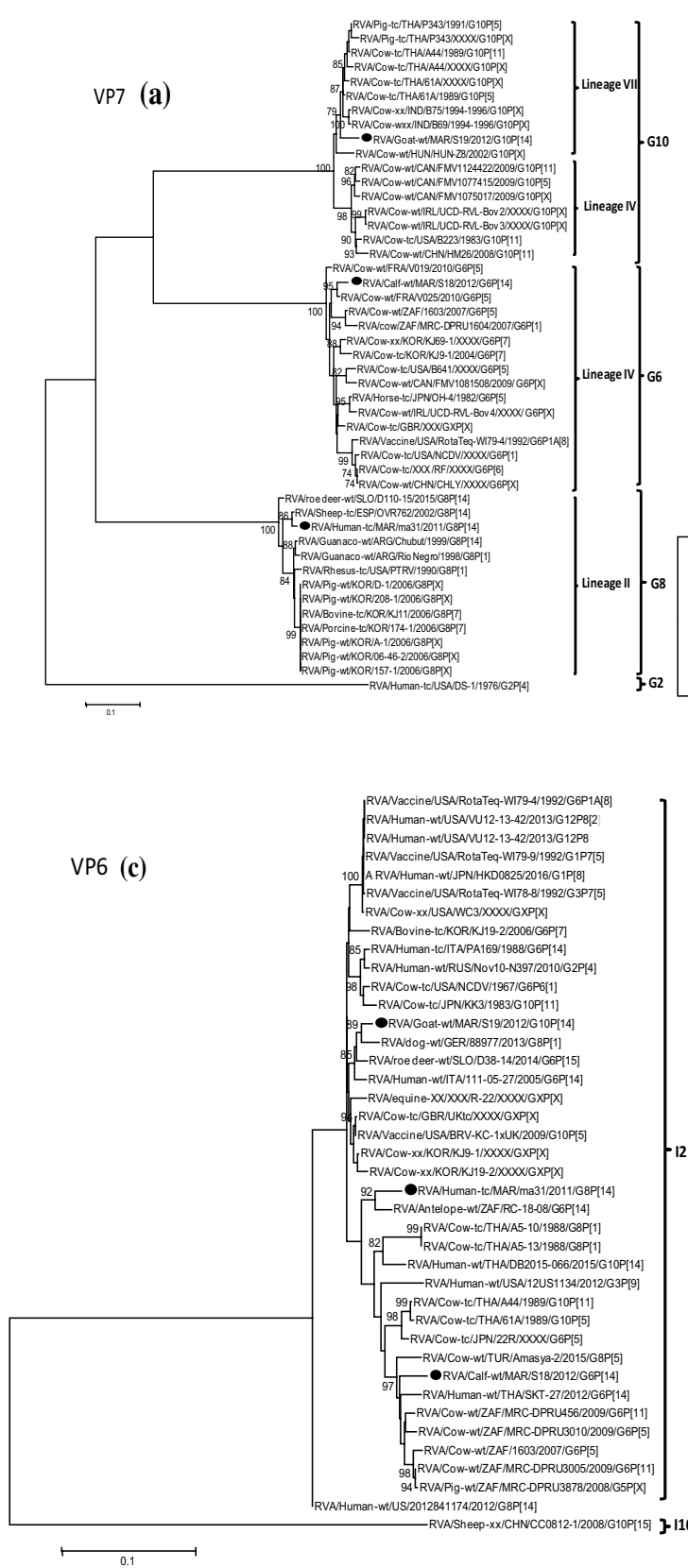

Fig. 1 Phylogenetic trees constructed from full nucleotide sequences of all 11 RVA gene segments of caprine RVA strain RVA/Goat-wt/ MAR/S19/2012/G10P[14] and bovine RVA strain RVA/Calf-wt/ MAR/S18/ 2012/G6P[14] with those of Moroccan human RVA strain ma31 and other RVAs. Moroccan strains are identified by a black cir- bovine-like human strain ma31 was found to be distantly related to other bovine and human strains in the T6 genotype (Fig. 1i).

The NSP4 genes of strains S18 and S19 exhibited the highest nucleotide sequence identity $(98.38 \%$ and $95.17 \%$, respectively) with the porcine strain P343 (G10P[5]) isolated in Thailand in 1991 and with the human strain BEF06018
RVACOCW-WAlNo/682007/68P[14] 100-RVAHUman-witTAPRA5712009/G10

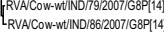

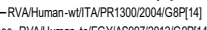

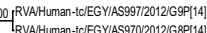
RVAHHuman-tcLEGYAS970:201268P(14)

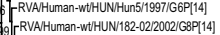

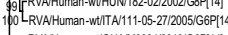

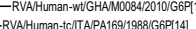
RVAHHUman-wWBELLB10925/1997/66P(14] - RVACAl-witMARIS182012/66P[14] 100 RVA Human-tcMAR/ma312011/68P(14) 71.RVAHUman-tCLAUSIMG6/1993/G6PF[14] -RVAHUMan-WWAAUSRCH272201263PPIT RVAHUMan-WWAUSWAGG.1200268PP(14)

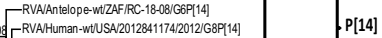

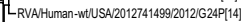
RVA/Human-tc/GBR/A66/1987/G 10P1[14] RVASheep-tc|ESPIOVR762:2002/68PP14]

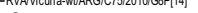

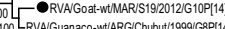
100 -

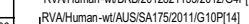
RVAHUMan-whitASSN585:2011/G10P[14]

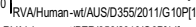

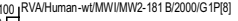

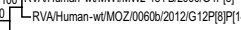
-RVAHUMan-WTTHASKT-272012/66P14 RVARabbit-wiCHNN5/1992/G3P[14]

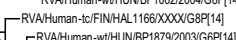

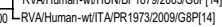
RVAAHuman-tc/JPNAU-1/1982/G3P3(9)

२.2

Lineagel
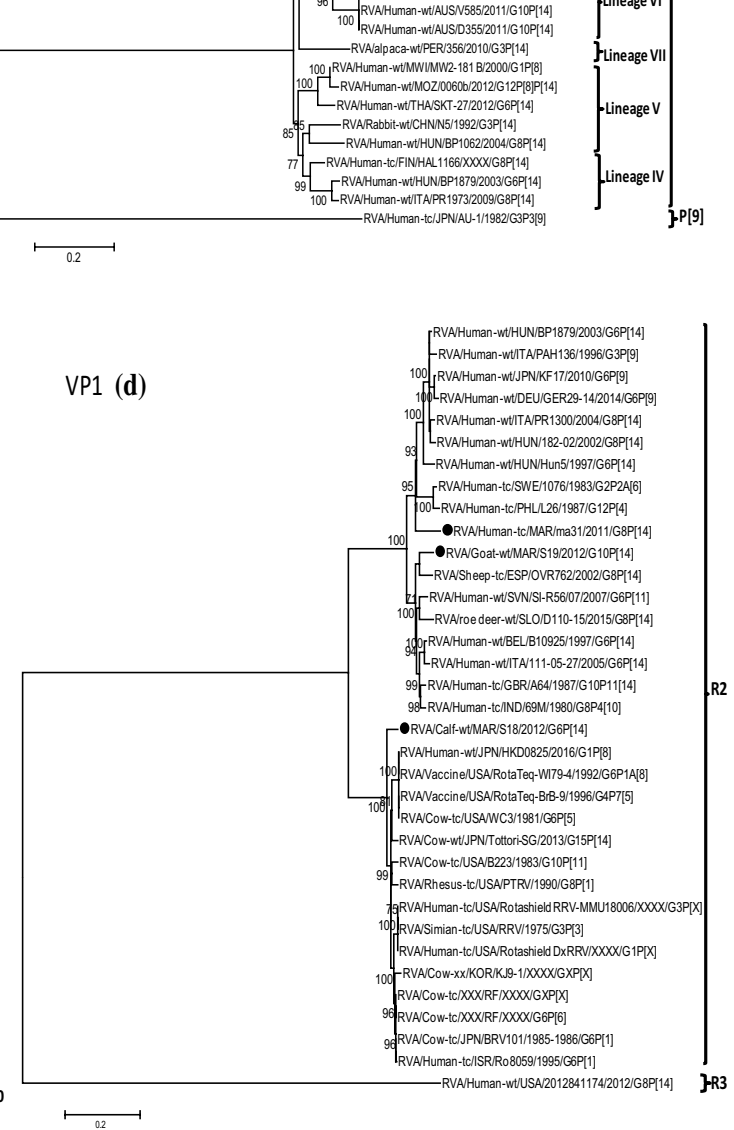

cle. Maximum likelihood method was used, with bootstrap at 1000 repetitions. Percent bootstrap support is indicated by the value at each node when the value was $80 \%$ or larger. Scale bars represent the number of nucleotide substitution per site 


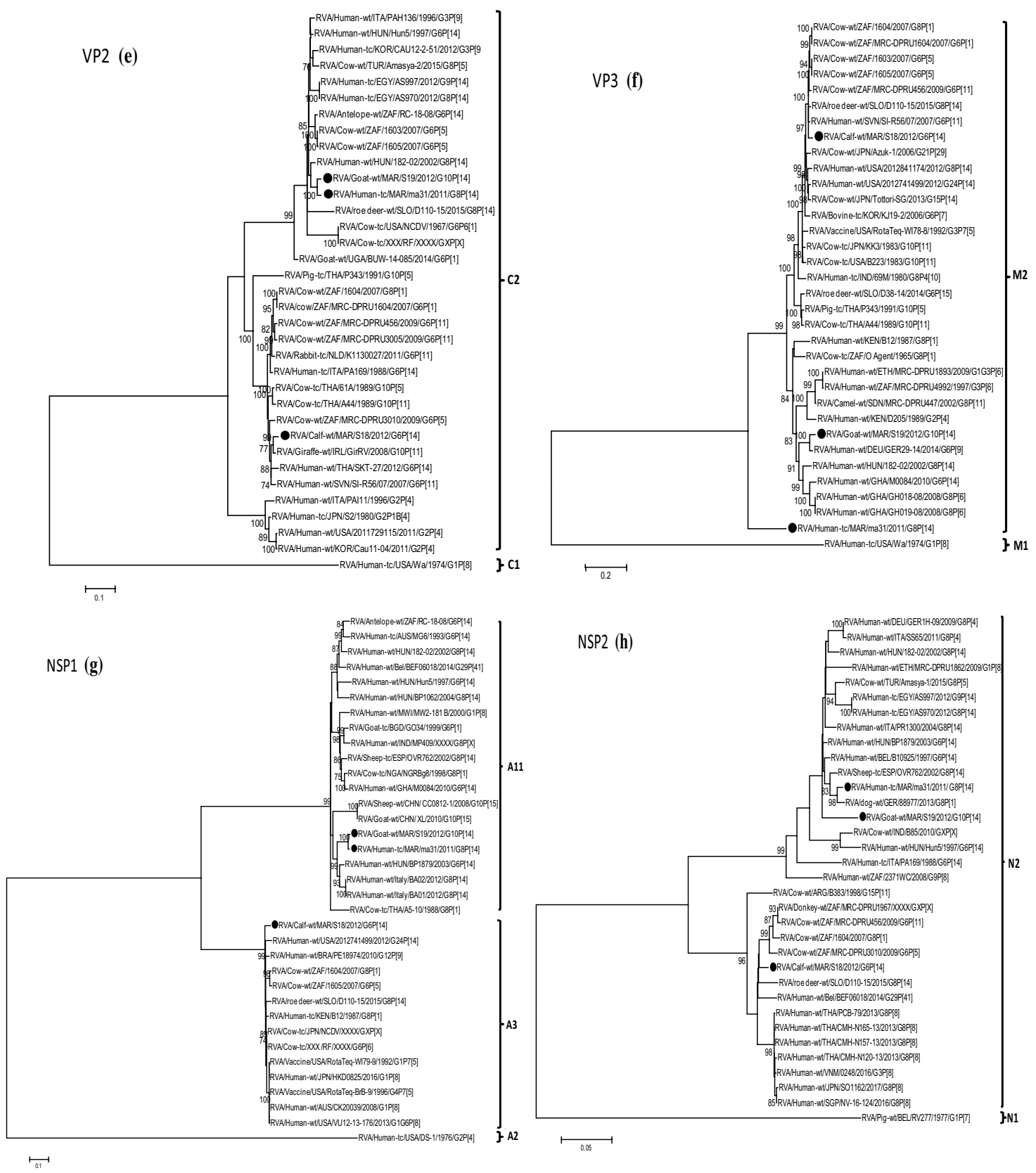

Fig. 1 (continued)

(G29P[41]) detected in Belgium in 2014, respectively. Phylogenetically, the human strain ma31 was found to be remotely related to $\mathrm{S} 18$ and $\mathrm{S} 19$ strains in the E2 genotype (Table 2 and Fig. 1j).

For the latest tree of the NSP5 gene, S18 strain matched closely with the dog strain GER/88,977/2013/G8P[1] (98.20\% nt identity), while the S19 strain clustered closely with the ovine strain ESP/OVR762/2002/G8P[14] (98.65\%) (Table 2). Phylogenetic analysis showed that the human strain ma31 was sandwiched between the two strains S18,
S19 and other human and bovine strains from different countries such as Germany, Japan, Turkey, Spain and Italy (Fig. 1k).

\section{Discussion}

The caprine and bovine rotaviruses isolated in 2012 and 2014 , in the nomadic livestock of the Bouaarfa region and analyzed in this study, revealed the existence of 3 circulating 

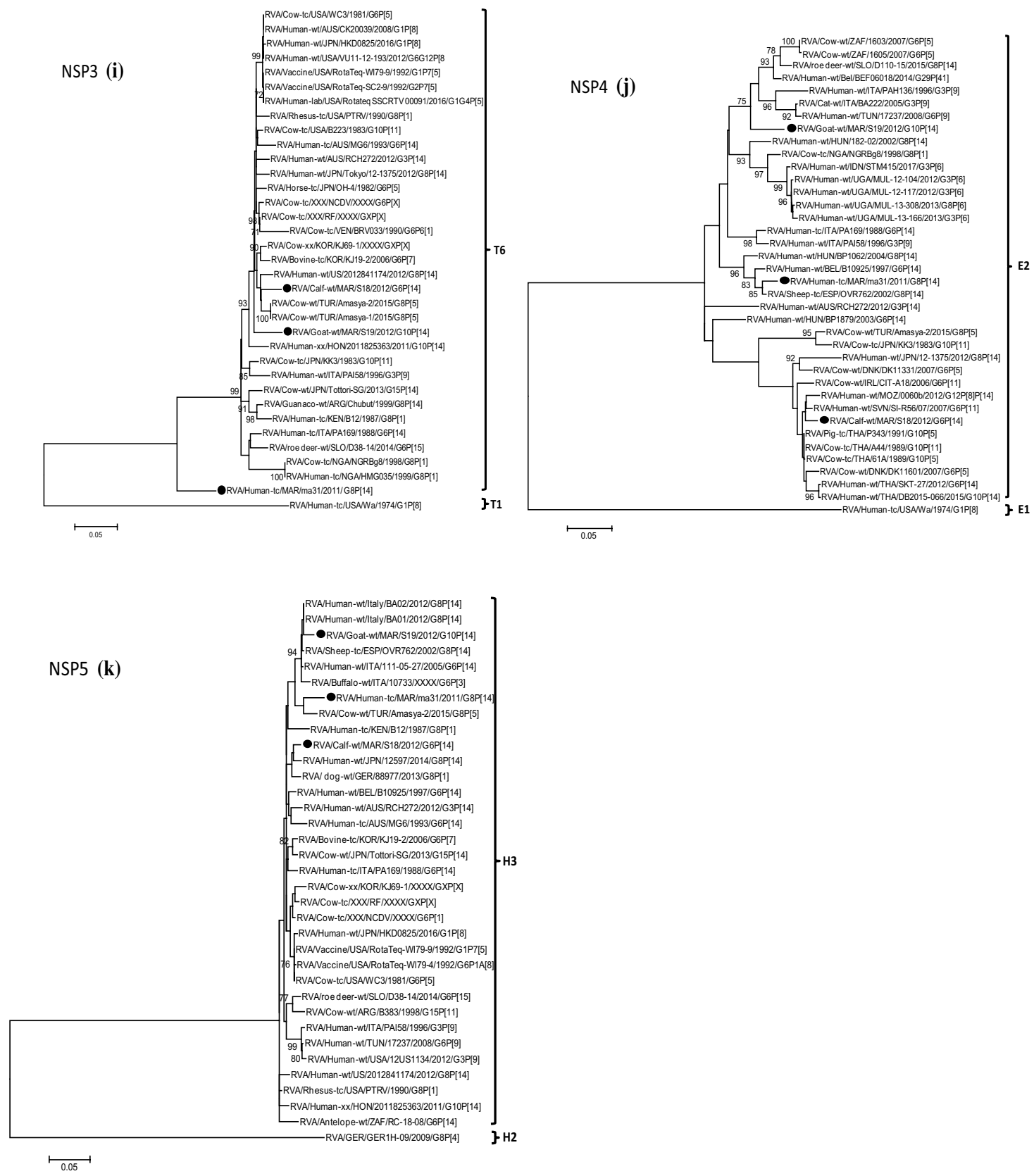

Fig. 1 (continued)

genotypes G6P[14], G10P[14] and G10P[5] in ruminants with a dominance of G6P[14]. This finding is in accordance with previously published data, which reported that the G6P[14] strains have been found so far in a South African group A caprine rotavirus [26]. Furthermore, the G6, G8, and $\mathrm{G} 10$ types have been detected in various RVA strains in cattle. The most common worldwide bovine genotype is G6, followed by G10 in Europe, Asia, Australia and Americas, and G8 in Africa [27].

Regarding P typing, $\mathrm{P}[14]$ and $\mathrm{P}[5]$ strains are prevalent in many countries around the world and the three combinations G6P[14], G10P[14] and G10P[5] are already described in many areas worldwide such as Europe, Australia and South Africa [26, 27]. In Morocco, a study conducted in 2016 in different farm dairies in the western part of the country during a severe neonatal calve diarrhea reported the circulation of two genotypes G10P[14] and G6P[5] [15]. Thus, despite the geographical position and lifestyle of the livestock, the genotypes circulating in cattle of both dairy farmers and nomads are more or less the same according to our study. Among these caprine and bovine strains genotyped, the complete genome sequences were determined for 


\begin{tabular}{|c|c|c|c|c|c|c|c|c|c|c|c|c|c|c|c|c|c|c|c|c|c|c|c|c|c|}
\hline & \multicolumn{11}{|c|}{$8-1$} & \multicolumn{2}{|c|}{$8-2$} & \multicolumn{9}{|c|}{$8-3$} & \multicolumn{3}{|c|}{$8-4$} \\
\hline & 100 & 146 & 148 & 150 & 188 & 190 & 192 & 193 & 194 & 195 & 196 & 180 & 183 & 113 & 114 & 115 & 116 & 125 & 131 & 132 & 133 & 135 & 87 & 88 & 89 \\
\hline Cow-wt/MAR/S18/2012/G6P[14] & $\mathrm{D}$ & L & $\mathrm{K}$ & G & $\mathrm{Y}$ & L & 1 & $\mathrm{~N}$ & $\mathrm{~N}$ & $\mathrm{D}$ & $\mathrm{N}$ & $T$ & $\mathrm{~N}$ & $\mathrm{~s}$ & $\mathrm{~N}$ & $T$ & $\mathrm{Q}$ & $\mathrm{T}$ & $\mathrm{s}$ & $\mathrm{N}$ & $\mathrm{N}$ & $\mathrm{s}$ & $\mathrm{T}$ & $Q$ & 1 \\
\hline Human-tc/MAR/ma31/2011/G8P[14] & . & . & . & . & . & . & . & . & . & . & . & . & . & . & . & . & . & . & . & . & . & . & . & . & . \\
\hline BOV/MAR/Bas1:2S/2014/P[14] & . & . & . & $\cdot$ & . & . & $\cdot$ & . & $\cdot$ & . & . & . & . & . & . & . & . & . & . & . & . & . & . & . & . \\
\hline BOV/MAR/Bas2:6S/2014/P[14] & . & . & . & $\cdot$ & . & . & $\cdot$ & . & . & . & . & . & . & . & $\cdot$ & . & . & . & . & . & . & . & . & . & $\cdot$ \\
\hline Goat-wt/MAR/S19/2012/G10P[14] & . & . & . & . & . & . & . & . & . & . & . & . & . & $\mathrm{P}$ & $S$ & . & . & . & . & . & $\mathrm{D}$ & . & . & . & V \\
\hline Guanaco-wt/ARG/Chubut/1999/G8P[14] & . & . & . & . & . & . & . & . & . & . & . & . & . & $\mathrm{P}$ & S & . & . & . & . & . & $\mathrm{D}$ & . & . & . & $\mathrm{V}$ \\
\hline Human-tc/TTA/PA169/1988/G6P[14] & . & . & . & . & . & . & . & . & . & . & . & . & . & . & . & . & . & . & . & . & . & . & . & . & . \\
\hline Human-wt/BEL/B10925/1997/G6P[14] & . & . & . & . & . & . & . & . & . & . & . & . & $\mathrm{D}$ & . & . & . & . & . & . & . & . & . & . & . & . \\
\hline Human-wt/THA/SKT-27/2012/G6P[14] & . & . & . & . & . & . & $\cdot$ & . & . & . & . & . & . & Q & . & . & $\cdot$ & . & . & . & D & . & . & . & $\cdot$ \\
\hline Sheep-tc/ESP/OVR762/2002/G8P[14] & . & . & . & . & . & . & . & . & . & . & . & . & . & . & . & . & . & . & . & . & $\mathrm{D}$ & . & . & . & . \\
\hline Human-wt/AUS/V585/2011/G10P[14] & . & . & . & . & . & . & . & . & . & . & . & . & . & . & . & & . & . & . & . & $\mathrm{D}$ & . & . & . & . \\
\hline Human-tc/GBR/A64/1987/G10P[14] & . & . & . & . & . & . & . & . & . & . & . & . & . & . & . & . & . & . & . & . & $\mathrm{D}$ & . & . & . & . \\
\hline Human-wt/GTM/2009726790/2009/G8P[14] & . & . & . & . & . & . & . & . & . & . & . & 1 & . & Q & . & 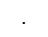 & . & A & . & . & D & . & . & . & A \\
\hline Human-wt/ITA/PR457/2009/G10P[14] & . & . & . & . & . & . & . & . & . & . & . & . & . & . & . & 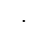 & . & . & . & . & $\mathrm{D}$ & . & . & . & . \\
\hline Vicuna-wt/ARG/C75/2010/G8P[14] & . & . & . & . & . & . & . & . & . & . & $\mathrm{D}$ & . & . & . & S & . & . & . & . & . & . & . & . & . & . \\
\hline Human-wt/GHA/M0084/2010/G6P[14] & . & . & . & . & . & . & . & . & . & . & . & . & . & . & . & . &. & . & . & . & D & . &. &. &. \\
\hline
\end{tabular}

Fig. 2 VP8* (VP4) antigenic epitopes analysis of strains S18 and S19 with selected P[14] strains. Moroccan strains are marked in bold

two strains S18 and S19 in order to gain more insights about the genetic relatedness between the latter and the human strain ma31. On whole-genomic analysis, the 11 segments of strains ma31, S18 and S19 were found to be relatively genetically diverse, but they share a widely conserved non-G genotype constellation (P[14]-I2-R2-C2-M2-(A3/11)-N2T6-E2-H3), which is commonly found and characteristic of artiodactyls bovine-like rotavirus strains [28, 29]. On the other hand, the phylogenetic analysis revealed that most genes of the three strains were related to those of bovine and bovine-like strains. The analysis of the VP8* antigenic epitopes for both S18, S19 and ma31 revealed a shared similarity with bovine, caprine, ovine and human strains from Morocco and other countries. Thus, these strains share the same genetic background that appears to be altered by independent interspecies transmission events (Fig. 2). This may indicate the probable conservation of function and structure of the antigenic epitopes among these strains.

All these findings, suggest that the human strain ma31 was a result of reassortment events between human and animal rotaviruses. It represents a case of interspecies transmission of RVA strains belonging to members of the Artiodactyla family including cattle, goat and camelids as has been discussed by Matthijnssens et al. [29] and others [30]. Many examples of the transfer of animal segments of the virus to humans were reported in different parts in the world [31-35]. Most of these segments were isolated either from porcine strains to human as demonstrated in Belem, Brazil by the VP6 gene sequencing [32], or by sequencing the VP7, VP4, VP6, and NSP4 genes to analyze the genetic relationship between human and animal rotaviruses (bovine and caprine) as described in two Danish and Brazilian studies [33-35]. The event of animal RVA segment transfer of the virus to human has been detected most frequently in low income countries where animals and humans are living closely, often sharing the same dwellings, as is the case of
Moroccan nomadic farmers. We have previously reported that the human strain ma31 was isolated from a child living in a rural region near the city of Rabat in frequent contact with cattle, goat and sheep [19], which may explain the isolation of the uncommon genotype G8P[14] never previously detected in Moroccan children. Thus seven gene segments (VP2, VP4, VP7, NSP1, NSP2, NSP3 and NSP4) of the strain demonstrated a high degree of similarity with strains of animal origin (caprine, bovine, ovine and dog). Three of these segments are very similar to those of S18 (VP4) and S19 (VP2, NSP1) strains isolated in Bouaarfa region in Morocco, while the other genes (VP7, NSP3, and NSP4) are close to the ovine Spanish strain OVR762 (G8P[14]) isolated in 2002 [7], and NSP2 similar to the dog strain 88977 (G8P[1]) isolated in Germany in 2013 [36]. The remaining four genes (VP1, VP3, VP6, and NSP5) presented a very close similarity to human RVA strains. In addition to that, the most frequent genotypes isolated in children and reported according to Benhafid et al. [37-40] are G1P[8], G9[P8], G2P [4], G4P[8] and G3P[8].

Therefore, the close relatedness of the three genes (VP4 for S18 with $100 \%$ nt identity, VP2 and NSP1 for S19 with $97.66 \%$ and $98.55 \%$ nt identity, respectively) of bovine and caprine strains to the human strain ma31, as well as the close relationship of three other genes with the ovine strain OVR762 (NSP4, NSP3 and VP7 with 97.6-99\% nt identity) and one gene (NSP2 with $98.5 \%$ nt identity) with a dog strain 88977 , suggest that ma31 may evolve through multiple reassortment events between human and ruminant rotaviruses. Our data indicates interspecies transmission between artiodactyl (bovine and/or caprine) and human rotaviruses and the zoonotic potential of rotavirus strains from ruminants seems to have a major significance since domestic animal species such as ruminants with direct contact to humans, can play a role in the spread of the virus by acting as natural reservoirs of the rotavirus [19, 29, 41, 42]. 
In conclusion, zoonotic transmission and gene segment reassortment between human and animal RVA do contribute to increase the diversity of human RVA strains [33]. The zoonotic studies are limited due to a poor disposability of genome sequences of animal RVA. Consequently it is important nowadays to expand monitoring of infections by rotaviruses to domestic animals, because its absence seems to reduce understanding of epidemiologic behavior of the virus. Thus and concerning this research, additional studies are needed with more samples taken from nomadic livestock in different regions of Morocco to obtain better informed results. Moreover, based on the results of this first study conducted on the livestock of nomadic farmers, and to avoid rotavirus infections causing neonatal diarrheic syndrome in nomadic calves and goats leading to important economic losses, a strategy for maternal rotavirus vaccination is recommended to boost lactogenic immunity and transfer passive antibodies to the neonate via colostrum and milk.

It is also imperative in Morocco, to create a surveillance system that can detect and identify animal rotaviruses, collect genetic data and estimate their zoonotic potential. Also, in parallel, the implementation of rotavirus surveillance strategies with an ongoing monitoring of genotypes in humans is crucial. These two actions will contribute significantly to the control and prevention of RVA infections in both humans and domestic animals, especially in regions with nomadic herders.

Acknowledgements This study was supported by the National Center for Scientific and Technical Research (CNRST) and the virology department. There was no involvement of the funding sources in carrying out this work from its conception to the data analysis, article writing and its submission for publication.

Author contributions NT, CL and EE conceived and designed the study. SA, HB and MM carried out the experiments. SA, MM and ME performed the data analysis. SA wrote the draft. NT, EE, MM, CL, HB and $\mathrm{ME}$ reviewed the manuscript. All the authors read the final version of the manuscript and approved it for publication.

\section{Compliance with ethical standards}

Conflict of interest The authors declare that they have no conflict of interest.

Ethical approval All fecal samples were collected from different nomadic farmers after authorization and in accordance with the Vet responsible, Dr. S. Fellahi.

\section{References}

1. Greenberg HB, Estes MK (2009) Rotaviruses: from pathogenesis to vaccination. Gastroenterology 136(6):1939-1951

2. Desselberger U (2014) Rotaviruses. Virus Res 190:75-96
3. Tate JE, Burton AH, Boschi-Pinto C, Steele AD, Duque J, Parashar UD (2012) 2008 estimate of worldwide rotavirus-associated mortality in children younger than 5 years before the introduction of universal rotavirus vaccination programmes: a systematic review and meta-analysis. Lancet Infect Dis 12(2):136-141

4. Estes MK (2013) Rotaviruses. In: Knipe DM, et al. (eds) Fields virology. Wolters Kluwer Health, Philadelphia

5. Estes MK, Kang G, Zeng CQ, Crawford SE, Ciarlet M (2001) Pathogenesis of rotavirus gastroenteritis. Novartis Found Symp 238(82-96):6

6. Kirkwood CD (2010) Genetic and antigenic diversity of human rotaviruses: potential impact on vaccination programs. J Infect Dis 202(Suppl):S43-48

7. Matthijnssens J, Ciarlet M, Heiman E, Arijs I, Delbeke T, McDonald SM, Palombo EA, Iturriza-Gomara M, Maes P, Patton JT, Rahman M, Van Ranst M (2008) Full genome-based classification of rotaviruses reveals a common origin between human Wa-Like and porcine rotavirus strains and human DS-1-like and bovine rotavirus strains. J Virol 82(7):3204-3219

8. Matthijnssens J, Ciarlet M, Rahman M, Attoui H, Banyai K, Estes MK, Gentsch JR, Iturriza-Gomara M, Kirkwood CD, Martella V, Mertens PP, Nakagomi O, Patton JT, Ruggeri FM, Saif LJ, Santos N, Steyer A, Taniguchi K, Desselberger U, Van Ranst M (2008) Recommendations for the classification of group A rotaviruses using all 11 genomic RNA segments. Arch Virol 153(8):1621-1629

9. Matthijnssens J, Ciarlet M, McDonald SM, Attoui H, Banyai K, Brister JR, Buesa J, Esona MD, Estes MK, Gentsch JR, IturrizaGomara M, Johne R, Kirkwood CD, Martella V, Mertens PP, Nakagomi O, Parreno V, Rahman M, Ruggeri FM, Saif LJ, Santos N, Steyer A, Taniguchi K, Patton JT, Desselberger U, Van Ranst M (2011) Uniformity of rotavirus strain nomenclature proposed by the Rotavirus Classification Working Group (RCWG). Arch Virol 156(8):1397-1413

10. Trojnar E, Sachsenroder J, Twardziok S, Reetz J, Otto PH, Johne R (2013) Identification of an avian group A rotavirus containing a novel VP4 gene with a close relationship to those of mammalian rotaviruses. J Gen Virol 94(1):136-142

11. Delogu R, Ianiro G, Morea A, Chironna M, Fiore L, Ruggeri FM (2016) Molecular characterization of two rare human G8P[14] rotavirus strains, detected in Italy in 2012. Infect Genet Evol 44:303-312

12. Dennis FE, Fujii Y, Haga K, Damanka S, Lartey B, Agbemabiese CA, Ohta N, Armah GE, Katayama K (2014) Identification of novel Ghanaian G8P[6] human-bovine reassortant rotavirus strain by next generation sequencing. PLoS ONE 9:6

13. Ghosh S, Kobayashi N (2011) Whole-genomic analysis of rotavirus strains: current status and future prospects. Future Microbiol 6(9):1049-1065

14. Doro R, Farkas SL, Martella V, Banyai K (2015) Zoonotic transmission of rotavirus: surveillance and control. Expert Rev Anti Infect Ther 13(11):1337-1350

15. Ennima I, Sebbar G, Harif B, Amzazi S, Loutfi C, Touil N (2016) Isolation and identification of group A rotaviruses among neonatal diarrheic calves. Morocco BMC Res Notes 9(1):261

16. Hassine-Zaafrane M, Ben Salem I, Sdiri-Loulizi K, Kaplon J, Bouslama L, Aouni Z, Sakly N, Pothier P, Aouni M, AmbertBalay K (2014) Distribution of G (VP7) and P (VP4) genotypes of group A bovine rotaviruses from Tunisian calves with diarrhoea. J Appl Microbiol 116(6):1387-1395

17. Ammar SSM, Mokhtaria K, Tahar BB, Amar AA, Redha BA, Yuva B, Mohamed HS, Abdellatif N, Laid B (2014) Prevalence of rotavirus (GARV) and coronavirus $(\mathrm{BCoV})$ associated with neonatal diarrhea in calves in western Algeria. Asian Pac J Trop Biomed 4:S318-S322 
18. Smail NL, Rezali L, Abdelhadi SA (2018) Etude préliminaire sur la mortalité de veaux âgés de 0 à 90 jours en région de Tiaret Algérie Ouest. Livestock Research for Rural Development Volume 30. Article\#98. https://www.lrrd.org/lrrd30/6/si_am300 98.html

19. Alaoui Amine S, Melloul M, El Alaoui MA, Touil N, El Fahime E (2019) Full-length genome analysis of the first human G8P[14] rotavirus strain from Morocco suggests evidence of zoonotic transmission. Virus Genes 55(4):465-478

20. Iturriza-Gomara M, Kang G, Gray J (2004) Rotavirus genotyping: keeping up with an evolving population of human rotaviruses. J Clin Virol 31(4):259-265

21. Simmonds MK, Armah G, Asmah R, Banerjee I, Damanka S, Esona M, Gentsch JR, Gray JJ, Kirkwood C, Page N, IturrizaGomara M (2008) New oligonucleotide primers for P-typing of rotavirus strains: strategies for typing previously untypeable strains. J Clin Virol 42(4):368-373

22. Maes P, Matthijnssens J, Rahman M, Van Ranst M (2009) RotaC: a web-based tool for the complete genome classification of group A rotaviruses. BMC Microbiol 9(238):1471-2180

23. Tamura K, Peterson D, Peterson N, Stecher G, Nei M, Kumar S (2011) MEGA5: molecular evolutionary genetics analysis using maximum likelihood, evolutionary distance, and maximum parsimony methods. Mol Biol Evol 28(10):2731-2739

24. Schwarz G (1978) Estimating the dimension of a model. Ann Stat 6(2):461-464

25. Tacharoenmuang R, Komoto S, Guntapong R, Ide T, Haga K, Katayama K, Kato T, Ouchi Y, Kurahashi H, Tsuji T, Sangkitporn S, Taniguchi K (2015) Whole genomic analysis of an unusual human G6P[14] rotavirus strain isolated from a child with diarrhea in Thailand: evidence for bovine-to-human interspecies transmission and reassortment events. PLoS ONE 10(9):e0139381. https://doi.org/10.1371/journal.pone.0139381

26. de Beer M, Steele D (2002) Characterization of the VP7 and VP4 genes of a South African group A caprine rotavirus. GenBank record. https://www.ncbi.nlm.nih.gov/nuccore/AY128709.1/andhttps://www.ncbi.nlm.nih.gov/nuccore/AY128708.1. Accessed Feb 2020

27. Valiakos GA, Chatzopoulos DCA, Tsokana CN (2017) Interspecies transmission of Rotaviruses among ruminants, dogs and humans: current facts and remarks. J Hellen Veterin Med Soc 68(2):123-130

28. Matthijnssens J, Van Ranst M (2012) Genotype constellation and evolution of group A rotaviruses infecting humans. Curr Opin Virol 2(4):426-433

29. Matthijnssens J, Potgieter CA, Ciarlet M, Parreno V, Martella V, Banyai K, Garaicoechea L, Palombo EA, Novo L, Zeller M, Arista S, Gerna G, Rahman M, Van Ranst M (2009) Are human $\mathrm{P}[14]$ rotavirus strains the result of interspecies transmissions from sheep or other ungulates that belong to the mammalian order Artiodactyla? J Virol 83(7):2917-2929

30. Jere KC, Mlera L, Page NA, van Dijk AA, O’Neill HG (2011) Whole genome analysis of multiple rotavirus strains from a single stool specimen using sequence-independent amplification and 454(R) pyrosequencing reveals evidence of intergenotype genome segment recombination. Infect Genet Evol 11(8):2072-2082
31. Bwogi J, Jere KC, Karamagi C, Byarugaba DK, Namuwulya P, Baliraine FN, Desselberger U, Iturriza-Gomara M (2017) Whole genome analysis of selected human and animal rotaviruses identified in Uganda from 2012 to 2014 reveals complex genome reassortment events between human, bovine, caprine and porcine strains. PLoS ONE 12(6): 0178855

32. Gabbay YB, Borges AA, Oliveira DS, Linhares AC, Mascarenhas JD, Barardi CR, Simoes CM, Wang Y, Glass RI, Jiang B (2008) Evidence for zoonotic transmission of group $\mathrm{C}$ rotaviruses among children in Belem. Braz J Med Virol 80(9):1666-1674

33. Luchs A, Cilli A, Morillo SG, de Carmona R et al (2012) Rare G3P[3] rotavirus strain detected in Brazil: possible human-canine interspecies transmission. J Clin Virol 54(1):89-92

34. Martella V, Banyai K, Matthijnssens J, Buonavoglia C, Ciarlet M (2010) Zoonotic aspects of rotaviruses. Vet Microbiol 140(3-4):246-255

35. Midgley SE, Hjulsager CK, Larsen LE, Falkenhorst G, Bottiger B (2012) Suspected zoonotic transmission of rotavirus group A in Danish adults. Epidemiol Infect 140(6):1013-1017

36. Sieg M, Rückner A, Köhler C, Burgener I, Vahlenkamp T (2014) A bovine G8P[1] group A rotavirus isolated from an asymptomatically infected dog. J Gen Virol. https://doi.org/10.1099/ vir.0.069120-0

37. Benhafid M, Elomari N, Azzouzi Idrissi M, Rguig A, Gentsch JR, Parashar U, Elaouad R (2014) Effect of monovalent rotavirus vaccine on rotavirus disease burden and circulating rotavirus strains among children in Morocco. J Med Virol 87(6):944-953

38. Benhafid M, Elomari N, Elqazoui M, Meryem AI, Rguig A, FilaliMaltouf A, Elaouad R (2013) Diversity of rotavirus strains circulating in children under 5 years of age admitted to hospital for acute gastroenteritis in Morocco, June 2006 to May 2009. J Med Virol 85(2):354-362

39. Benhafid M, Youbi M, Klena JD, Gentsch JR, Teleb N, Widdowson MA, Elaouad R (2009) Epidemiology of rotavirus gastroenteritis among children $<5$ years of age in Morocco during 1 year of sentinel hospital surveillance, June 2006-May 2007. J Infect Dis 1(200):605048

40. El Qazoui M, Oumzil H, Baassi L, El Omari N, Sadki K, Amzazi S, Benhafid M, El Aouad R (2014) Rotavirus and norovirus infections among acute gastroenteritis children in Morocco. BMC Infect Dis 14:300-300

41. Donato CM, Manuelpillai NM, Cowley D, Roczo-Farkas S, Buttery JP, Crawford NW, Kirkwood CD (2014) Genetic characterization of a novel G3P[14] rotavirus strain causing gastroenteritis in 12 year old Australian child. Infect Genet Evol 25:97-109

42. Mullick S, Mukherjee A, Ghosh S, Pazhani GP, Sur D, Manna B, Nataro JP, Levine MM, Ramamurthy T, Chawla-Sarkar M (2013) Genomic analysis of human rotavirus strains G6P[14] and G11P[25] isolated from Kolkata in 2009 reveals interspecies transmission and complex reassortment events. Infect Genet Evol $14: 15-21$

Publisher's Note Springer Nature remains neutral with regard to jurisdictional claims in published maps and institutional affiliations. 